\section{Endoscopic ultrasound-guided fine-needle aspira- tion diagnosis of mixed endocrine somatostatinoma of the minor papilla in von Recklinghausen disease}
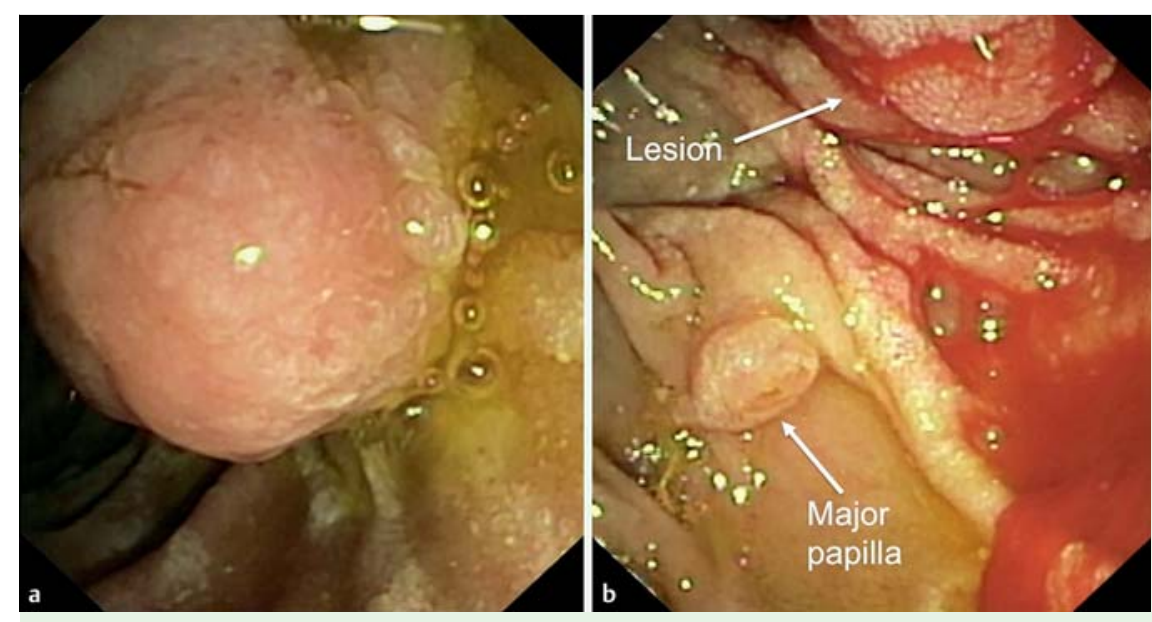

Fig. 1 Mixed endocrine somatostatinoma of the minor papilla in a patient with von Recklinghausen disease. a Endoscopic image of the lesion in the second part of the duodenum. b Normal major papilla with lesion localized in the area of the minor papilla.

Von Recklinghausen disease (VRD) is an autosomal-dominant disorder with variable penetrance. VRD is associated with a variety of benign and malignant neoplastic lesions [1]. The association with duodenal neuroendocrine tumors, particularly somatostatinomas, is widely recognized [1-3]. Mixed endocrine tumors are a particular category of neuroendocrine tumors and include at least two distinct tumor populations, one of which is endocrine $[3,4]$. We describe a case of mixed neuroendocrine tumor with somatostatin expression arising from the minor papilla in a patient with VRD, diagnosed by endo- scopic ultrasound-guided fine-needle aspiration (EUS-FNA).

A 61-year-old woman with VRD was referred to our institute for endoscopic resection of an adenomatous polyp of the major papilla. Duodenoscopy revealed a $2.5-\mathrm{cm}$ polyp in the area of the minor papilla ( $\bullet$ Fig. 1 a,b). EUS showed that the lesion arose from the submucosa of the minor papilla and obstructed the dorsal pancreatic duct ( Fig.2a). Endoscopic biopsy and EUS-FNA with a standard 19-gauge needle were done ( $\bullet$ Fig.2b). While superficial biopsy specimens showed tubular adenoma with mild dysplasia ( $\bullet$ Fig.3a), small core specimens obtained with EUS-FNA showed small monomorphic cubic cells with immunohistochemical expression of chromogranin, synaptophysin, and somatostatin ( Fig.3b). Computed tomography showed two hypervascular lesions, 25 and $4 \mathrm{~mm}$ in size, in the second part of the duodenum ( Fig.4), with the largest one obstructing the dorsal pancreatic duct in the context of pancreas divisum. The results of an octreotide scan were negative. Surgery was recommended, but the patient refused.

The diagnosis was difficult because of the presence of a mixed endocrine tumor composed of epithelial adenoma and somatostatinoma. A precise diagnosis is important because adenomas with mild dysplasia are an indication for endoscopic resection, but somatostatinomas associated with VRD are an indication for surgery, especially when the diameter of a tumor is larger than $2 \mathrm{~cm}$, because of the high degree of malignant potential with regional lymph node involvement [4-6]. In this case, both morphologic EUS and FNA were essential for a correct diagnosis and management, and they should be considered for all patients with VRD and duodenal lesions.

\section{Endoscopy_UCTN_Code_CCL_1AZ_2AB}

Competing interests: None

\section{Luca Barresi ${ }^{1}$, Ilaria Tarantino ${ }^{1}$, Dario Ligresti ${ }^{1}$, Rosa Liotta ${ }^{2}$, Gabriele Curcio ${ }^{1}$, Antonino Granata ${ }^{1}$, Gianluca Marrone ${ }^{3}$, Mario Traina'}

${ }^{1}$ Endoscopy Service, Department of Diagnostic and Therapeutic Services, Mediterranean Institute for Transplantation and Advanced Specialized Therapies (ISMETT), Palermo, Italy

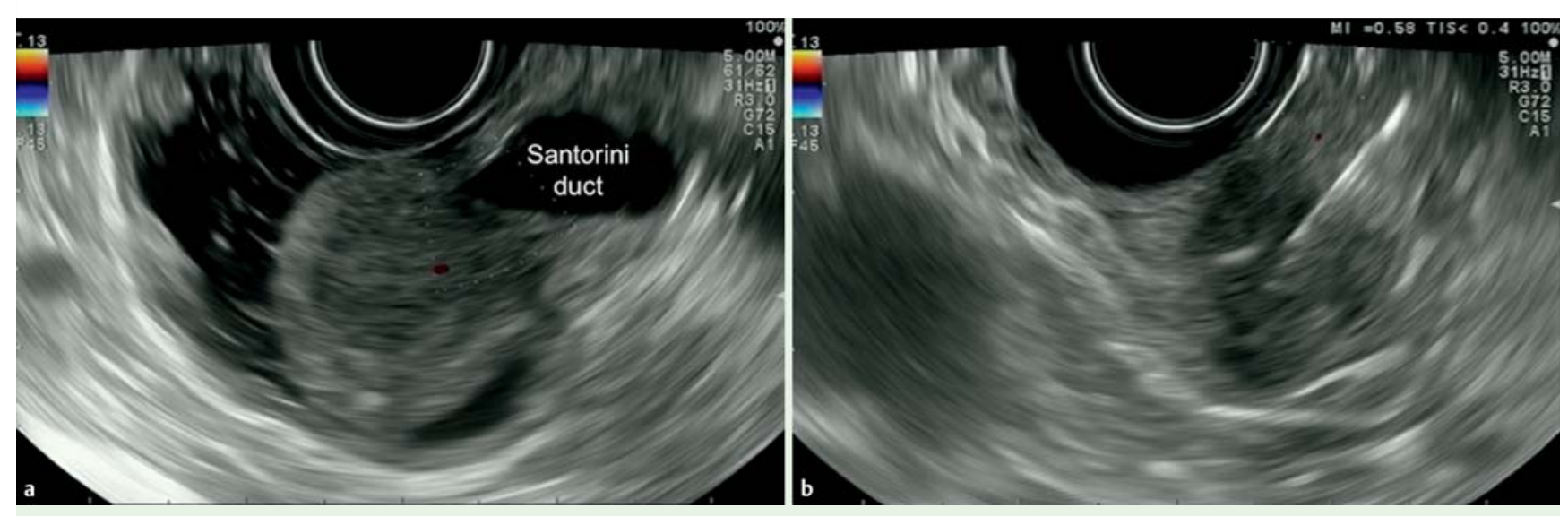

Fig. 2 a Endoscopic ultrasound (EUS) image of a hypoechoic submucosal lesion of the minor papilla obstructing a dilated duct of Santorini. b EUS-guided fineneedle aspiration with a standard 19-gauge needle. 


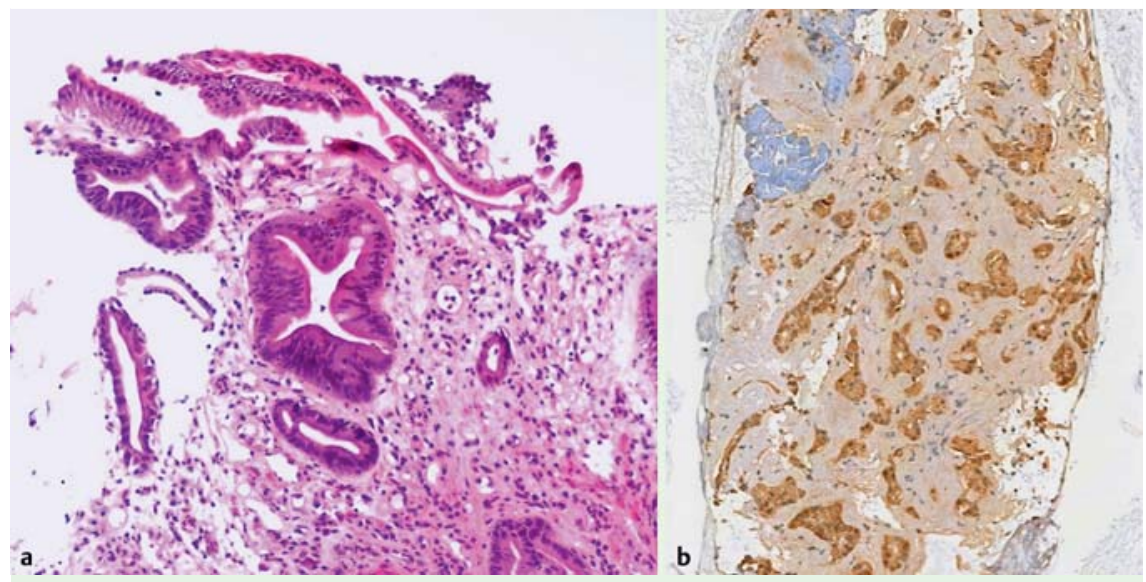

Fig. 3 a Histologic section of a duodenal biopsy specimen stained with hematoxylin and eosin shows mild epithelial dysplasia on the luminal surface. b Core specimen from endoscopic ultrasound-guided fine-needle aspiration shows small micronodular-trabecular aggregates of endocrine cells within fibrohyalinotic tissue. The endocrine cells are positive for somatostatin immunohistochemical stain.

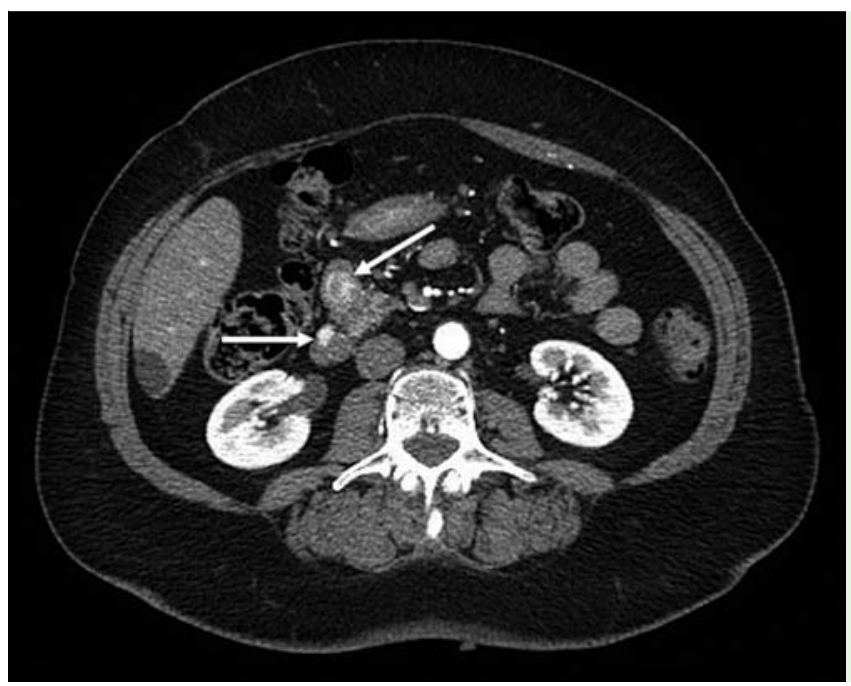

Fig. 4 Computed tomographic scan showing two hypervascular lesions in the second part of the duodenum (arrows).
2 Pathology Service, Department of Diagnostic and Therapeutic Services, Mediterranean Institute for Transplantation and Advanced Specialized Therapies (ISMETT), Palermo, Italy

${ }^{3}$ Radiology Service, Department of Diagnostic and Therapeutic Services, Mediterranean Institute for Transplantation and Advanced Specialized Therapies (ISMETT), Palermo, Italy

\section{References}

1 Basile U, Cavallaro G, Polistena A et al. Gastrointestinal and retroperitoneal manifestations of type 1 neurofibromatosis. J Gastrointest Surg 2010; 14: 186-194

2 Fendrich V, Ramaswamy A, Slater EP et al. Duodenal somatostatinoma associated with Von Recklinghausen's disease. J Hepatobiliary Pancreat Surg 2004; 11: 417-421

3 Capella C, La Rosa S, Uccella S et al. Mixed endocrine-exocrine tumors of the gastrointestinal tract. Semin Diagn Pathol 2000; 17: 91-103

4 Deschamps L, Dokmak S, Guedj $N$ et al. Mixed endocrine somatostatinoma of the ampulla of Vater associated with a neurofibromatosis type 1: a case report and review of the literature. JOP 2010; 11: 64-68

5 Burke AP, Sobin LH, Federspiel BH et al. Carcinoid tumors of the duodenum. A clinicopathologic study of 99 cases. Arch Pathol Lab Med 1990; 114: 700 - 704

6 Rorstad 0 . Prognostic indicators for carcinoid neuroendocrine tumors of the gastrointestinal tract. J Surg Oncol 2005; 89 $151-160$

Bibliography

DOI http://dx.doi.org/

10.1055/s-0034-1390868

Endoscopy 2014; 46: E664-E665

(c) Georg Thieme Verlag KG

Stuttgart $\cdot$ New York

ISSN 0013-726X

\section{Corresponding author}

Luca Barresi, MD

Endoscopy Service

ISMETT

Via Tricomi 1

Palermo 90127

Italy

Fax: +390912192400

Ibarresi@ismett.edu 